\title{
USERS' PERCEPTION REGARDING SCIENTIFIC PRODUCTION IN THE FACULTY OF MEDICAL SCIENCES
}

\author{
Dr. Jorge Daher Nader ${ }^{1} \bowtie$, Dr. Amelia Patricia Panunzio ${ }^{1}$, Dr. Marlene Hernández \\ Navarro ${ }^{2}$ \\ 1 Professor at the University of Guayaquil, Ecuador \\ 2 University of Zulia, Venezuela
}

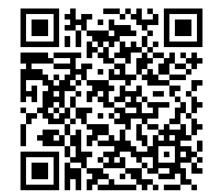

DOI: https://doi.org/10.29121/granthaalayah.v8.i9.2020.1676

Article Type: Research Article

Article Citation: Dr. Jorge Daher Nader, Dr. Amelia Patricia Panunzio, and Dr. Marlene Hernández

Navarro. (2020). USERS'

PERCEPTION REGARDING

SCIENTIFIC PRODUCTION IN THE

FACULTY OF MEDICAL SCIENCES.

International Journal of Research GRANTHAALAYAH, 8(9), 395-403.

https://doi.org/10.29121/granthaa layah.v8.i9.2020.1676

Received Date: 15 September 2020

Accepted Date: 30 September 2020

Keywords:

Perception

Productivity

Scientific

Quality

\section{ABSTRACT}

Higher Education Institutions in all regions must submit to internal and external evaluations carried out with transparency, carried out by independent experts. In the CEAACES evaluation model, research is included as one of the most important processes within university management. An evaluation was carried out at the University of Guayaquil in 2013, being evaluated in category " $\mathrm{D}$ ". The scientific production of the FCM was $2 \%$, it ranked last in all the criteria, and it did not meet the requirements for accreditation, due to the tiny percentage that was maintained. Users' perception regarding scientific production is very important for the faculty of medical sciences.

\section{INTRODUCTION}

Scientific production is an indicator of the quality of processes in the university environment, so it must be increased by virtue of the results of the work carried out by research teachers and studentsthe identification of the perception of the users regarding the scientific production, which together it will allow to establish the strategies to propose the strengthening model in this area. Theoretical and empirical methods will be used, within the former: deductive and within the latter: observation, interview, survey and questionnaire. The development of a model for the strengthening of scientific production within Research Management is proposed as a way to establish mechanisms for the dissemination of researchers' results

According to goal objective about identify the perception of teachers, students and graduates of the Faculty of Medical Sciences of the University of Guayaquil regarding scientific production 
Table 1: Mean and standard deviation for the indicators of the USER PERCEPTION DIMENSION on scientific production

\begin{tabular}{|c|c|}
\hline Subdimensions & Mean \pm DS \\
\hline Teachers' perception & $2,49 \pm 1,274$ \\
Student perception & $3,61 \pm 1,330$ \\
Perception of graduates & $2,79 \pm 1,241$ \\
\hline
\end{tabular}

Own Elaboration (Daher J. 2019)

Table 1.- shows in a general way the perception of teachers, students and graduates, according to the mean score obtained from the responses given by the actors participating in the study; As can be seen, the means and SD obtained are between the medium levels ( 2 to 3.99) and low (1 to 1.99). Which denotes that there are shortcomings in the Faculty of Medical Sciences regarding the perception of users about scientific production. The results obtained for each subdimension and respective indicators are detailed below.

Below is the analysis of the indicators of the subdimension perception of teachers on scientific activity in the Faculty of Medical Sciences.

Table 2: Mean and standard deviation for the indicators of the subdimension Perception of The Scientific Activity of Teachers

\begin{tabular}{|c|c|}
\hline Indicators & \\
\hline Training on student scientific activity \pm SD & $2,90 \pm 1,264$ \\
Training on writing scientific articles & $2,48 \pm 1,264$ \\
Budget allocation for publishing & $1,72 \pm 1,039$ \\
Laboratory operation & $1,32 \pm, 843$ \\
Training for project development & $1,66 \pm 1,050$ \\
Participation in research networks & $3,11 \pm 1,508$ \\
Participation in scientific societies & $2,49 \pm 1,198$ \\
Accompaniment in the development of research projects & $2,39 \pm 1,592$ \\
Budget allocation to execute projects & $2,91 \pm 1,358$ \\
Motivation towards research. & $3,48 \pm 1,409$ \\
Knowledge of the lines of research. & $2,24 \pm 1,333$ \\
Disclosure of magazines to publish & $2,94 \pm 1,441$ \\
\hline
\end{tabular}

Own Elaboration (Daher J. 2019) $n=197$ teachers

Regarding training on student scientific activity and on writing scientific articles, the mean and SD obtained were $2.90 \pm 1.244$ and $2.48 \pm 1.264$ respectively (medium level), which denotes that the training received by the students is insufficient. teachers in these topics, on the other hand training for research projects was also shown at a low level $1.66 \pm 1.050$. These results differ from those published by Mendoza Valladares, J, L) and Ruth Roux 2016) who refer that the continuous professional development of teachers is considered a fundamental piece for the development of countries. Starting from the understanding that teachers are the ones who train future members of a society by interacting directly with students, it is recognized that their continuing education is crucial to strengthen the development of society.

The development of policies and strategies for continuous professional improvement not only allows teachers to stay at the forefront and continue with their preparation throughout their careers, but also helps teachers offer quality academic and research services that favorably influence the training of students (Mendoza Valladares, J, L and Ruth Roux 2016).

The training of trainers program established at the university does not include the subject of writing scientific articles or student scientific activity, this program includes the subject of preparing degree projects, despite these, this does not justify the poor teacher improvement in this area .

When inquiring about the budget allocation and the operation of laboratories and physical spaces for research, levels were obtained below $1.72 \pm 1.039$ and $1.32 \pm .843$, which indicates that there are serious deficiencies in this area, on the other hand the allocation of budget to execute the projects obtained an average of $2.91 \pm 1.358$, these data behave in a similar way to the investigation entitled Perception and attitudes towards scientific research, 
(Ortega Carrasco, RJ, 2018) who obtained as a result that less than $20 \%$ of those surveyed consider that their faculty has infrastructure suitable for scientific research, which has been significantly influenced by the lack of budget allocated for research.

Participation in research networks and scientific societies was another indicator to take into account, the mean and SD obtained were $3.11 \pm 1.508$ and $2.49 \pm 1.198$, medium and low level respectively, in these indicators it is necessary to point out that constitute a flaw today. The participation of teachers in scientific societies is very scarce. These results coincide with González SJ, 2017 who, in a study entitled Scientific production of the medical school of a Peruvian university in SCOPUS and Pubmed, suggests that the scarce scientific production can be explained by a lack of collaboration networks between institutions and researchers, the shortcomings in the training of students and teachers on research topics, the low availability of research funds and the precarious research culture. The support in the development of research projects as well as the budget allocation for them obtained an average of $2.39 \pm 1.592$ and $2.91 \pm 1.358$ (medium level) respectively, which denotes that the support given to them is insufficient. performs the teachers for the development of research projects by the department's research department, as well as the budget allocation, both elements are essential to achieve quality scientific activity.

On the other hand, the motivation towards research obtained an average of $3.48 \pm 1.409$, the teachers in many cases are motivated, which could negatively influence the insufficient knowledge in research methodology that in some cases exists. Knowledge of the lines of research and the dissemination of the journals in which to publish obtained a mean of $2.21 \pm 1.333$ and $2.94 \pm 1.441$ (medium level) respectively. The need for a greater socialization of the lines of research and of the journals where to publish in the Faculty of Medical Sciences is notorious.

In the results obtained when surveying the teachers, the time of dedication could have influenced, since the highest percentage was represented by part-time teachers, a total of 97 teachers for $49.2 \%$. These teachers have less time dedicated to research activities, which may be an influencing factor in these results. On the other hand, a total of 57 part-time teachers had a master's degree and 40 were specialists, which also at the author's discretion could affect scientific production.

Table 3: Anova of the indicators of the teachers' perception subdimension

\begin{tabular}{|c|c|c|c|c|c|c|}
\hline \multicolumn{7}{|c|}{ ANOVA } \\
\hline & & Sum of squares & gl & Mean quadratic & $\mathrm{F}$ & Sig. \\
\hline \multirow[t]{3}{*}{ Training on student scientific activity } & Between groups & 52,344 & 4 & 13,086 & 9,633 & 000 \\
\hline & Within groups & 260,824 & 193 & 1,358 & & \\
\hline & Total & 313,168 & 197 & & & \\
\hline \multirow[t]{3}{*}{ Training on writing scientific articles } & Between groups & 23,994 & 4 & 5,999 & 3,983 & 004 \\
\hline & Within groups & 289,153 & 193 & 1,506 & & \\
\hline & Total & 313,147 & 197 & & & \\
\hline \multirow[t]{3}{*}{ Laboratory operation } & Between groups & 36,830 & 4 & 9,208 & 17,268 &, 000 \\
\hline & Within groups & 102,378 & 193 &, 533 & & \\
\hline & Total & 139,208 & 197 & & & \\
\hline \multirow[t]{3}{*}{ Training for the preparation of projects } & Between groups & 46,431 & 4 & 11,608 & 13,127 & 000 \\
\hline & Within groups & 169,782 & 193 &, 884 & & \\
\hline & Total & 216,213 & 197 & & & \\
\hline \multirow[t]{3}{*}{ Participation in research networks } & Between groups & 26,072 & 4 & 6,518 & 2,983 & 020 \\
\hline & Within groups & 419,471 & 193 & 2,185 & & \\
\hline & Total & 445,543 & 197 & & & \\
\hline \multirow[t]{3}{*}{ Participation in scientific societies } & Between groups & 14,138 & 4 & 3,534 & 2,541 & 041 \\
\hline & Within groups & 267,101 & 193 & 1,391 & & \\
\hline & Total & 281,239 & 197 & & & \\
\hline \multirow[t]{3}{*}{ Accompaniment in the development of projec } & sBetween groups & 37,303 & 4 & 9,326 & 3,898 & 006 \\
\hline & Within groups & 459,377 & 193 & 2,393 & & \\
\hline & Total & 496,680 & 197 & & & \\
\hline \multirow[t]{2}{*}{ Budget allocation to execute projects } & Between groups & 33,324 & 4 & 8,331 & 4,874 &, 011 \\
\hline & Within groups & 328,209 & 193 & 1,709 & & \\
\hline
\end{tabular}


Users' Perception Regarding Scientific Production in The Faculty of Medical Sciences

\begin{tabular}{|c|c|c|c|c|c|c|}
\hline & Total & 361,533 & 197 & & \\
\hline \multirow{2}{*}{ Motivation towards research } & Between groups & 19,325 & 4 & 4,831 & 2,508 &, 043 \\
\cline { 2 - 7 } & Within groups & 369,863 & 193 & 1,926 & & \\
\cline { 2 - 7 } & Total & 389,188 & 197 & & & \\
\hline \multirow{2}{*}{ Knowledge of the research lines } & Between groups & 33,694 & 4 & 8,423 & $5,141,001$ \\
\cline { 2 - 7 } & Within groups & 314,611 & 193 & 1,639 & & \\
\cline { 2 - 7 } & Total & 348,305 & 197 & & & \\
\hline \multirow{2}{*}{ Disclosure of magazines to publish } & Between groups & 1,402 & 4 &, 350 &, 166 &, 956 \\
\hline & Within groups & 405,867 & 193 & 2,114 & & \\
\hline & Total & 407,269 & 197 & & & \\
\hline
\end{tabular}

Own Elaboration (Daher J. 2019)

When analyzing the ANOVA applied to the indicators of the teachers' perception subdimension, it can be observed that there are statistically significant differences in the indicators: training on student scientific activity, operation of laboratories and training for the preparation of projects, since the results were be less than 0.001 . The following is Tukey's test for these indicators

Below are the results of the instrument applied to students to inquire about their perception regarding student scientific activity in the Faculty of Medical Sciences.

Table 3: Mean and standard deviation for the indicators of the PERCEPTION OF SCIENTIFIC ACTIVITY subdimension. Questionnaire for students

\begin{tabular}{|c|c|}
\hline Indicators & Mean \pm SD \\
\hline Training for project development & $3,77 \pm 1,292$ \\
Training on writing scientific articles. & $3,66 \pm 1,280$ \\
Budget allocation for publishing & $3,38 \pm 1,341$ \\
Laboratory operation & $3,52 \pm 1,441$ \\
Accompaniment in the development of research projects & $3,64 \pm 1,335$ \\
Budget allocation to execute projects & $3,39 \pm 1,373$ \\
Knowledge of the research lines & $3,64 \pm 1,310$ \\
Motivation towards research. & $3,81 \pm 1,280$ \\
Disclosure of research activities & $3,85 \pm 1,265$ \\
Availability of time for research & $3,56 \pm 1,347$ \\
Disclosure of magazines to publish & $3,46 \pm 1,387$ \\
Empowerment of teachers of student scientific activity & $3,64 \pm 1,312$ \\
\hline
\end{tabular}

Own Elaboration (Daher J. 2019) $n=370$ students

The main results of this research indicate that there are weaknesses in the development of training for students to develop and present projects in instances of calls, as well as for the development of scientific articles. The mean value and SD obtained were $3.77 \pm 1.292$ (medium level) and $3.66 \pm 1.281$ (medium level) respectively. These results coincide with Sánchez M, 2015 who obtained the result that only five of the surveyed students have published a manuscript in a journal and only one has presented the results of his study in a scientific congress.

Thus, the results obtained in relation to the training to prepare projects and write scientific articles are similar to those obtained in a study entitled Perception and attitudes towards scientific research by Ortega Carrasco, RJ, 2018 in which the most important findings identified were: weaknesses in the development of capacities of students to present projects in instances of calls; few training related to project development, little participation in scientific dissemination events; little use of scientific articles by teachers in their chairs; as well as the need for greater emphasis on teaching the scientific method. There is also agreement with Molina, et al. 2008 who conclude that the training obtained in the undergraduate, directed to the writing and publication process, is deficient and that it also presents limitations such as the lack of support and university training. This occurs despite the fact that the work they do is considered to be of acceptable quality to be published, and they have adequate training in research methodology 
In relation to the laboratories and physical spaces for research and the allocation of the budget to publish, a mean and SD of $3.52 \pm 1.441$ and $3.38 \pm 1.341$ were obtained, both at a medium level, so it is observed that there are deficiencies according to what the students refer in the questionnaire applied to them since the infrastructure destined for this purpose is not enough. These results coincide with Ortega Carrasco, RJ, 2018, who in his research entitled Perception and attitudes towards scientific research obtained as a result that in terms of infrastructure and networks, students responded by $42 \%$ that the faculty has a research department, however, less than $20 \%$ of those surveyed consider that their faculty has adequate infrastructure for scientific research, and only about $30 \%$ of students indicate that their institution has links with other organizations to carry out scientific research. At the institutional level, the promotion of the research unit is insufficient, and above all, of linking research activities with students.

When inquiring about the students' knowledge of the research lines, a mean and Ds of $3.64 \pm 1.310$ were obtained, a medium level, which denotes that the dissemination of the research lines by the teachers is still insufficient. The disclosure of the same should be promoted so that any investigation that is carried out is framed within a line of investigation. According to Fernández Espinosa and Villavicencio Aguilar (2017), research must remain as a transversal axis during the training of undergraduate students, bringing them closer to research from the first years to enhance their investigative skills.

In this regard, Álvarez Icaza, 2011 mentions that "one of the main problems of providing students with an experience in research and lines of research, the journals where to publish, as well as the research activities carried out in the faculty, which contributes to increasing the motivation of students towards scientific activity.

Regarding motivation for scientific research, a mean $3.81 \pm 1.280$ was obtained, a medium level, it is evident that the motivation of students in this aspect is not enough. These results are similar to those obtained by Bascó, 2015, who in his study, when exploring whether students had received motivation and tutoring offer, those in VII and VIII semesters expressed having received this type of tutoring and motivation from teachers, with a statistical significance $(\mathrm{p}<0.05)$. This data is also similar to that obtained when inquiring from teachers about this indicator. Both want to carry out research, which in many cases could have a negative influence is insufficient knowledge, limited time and limited availability of resources.

Regarding the dissemination of research activities, an average of $3.85 \pm 1.265$ was obtained, these data are similar to a study carried out by Ortega Carrasco, RJ, 2018 where just over $14 \%$ of students know the calls related to scientific research offered by the National Council of Science and Technology (CONACYT), data that reveals the ignorance of the multiple opportunities offered by the most important institution in terms of promoting scientific research in the country, in turn this may be limiting the motivation to take research as a career to follow due to lack of information

The availability of time for research was another investigated indicator in which the mean and SD was $3.56 \pm$ 1.347 , for a medium level, which indicates that students do not have enough time for scientific activity according to what refer in the questionnaire. This result coincides with a study carried out by Hernández and Losada, 2017 in which these authors state that one of the factors that influence the scarce student scientific production is that students have little time to investigate, due to the large number of tasks oriented by teachers and the hourly load that is very intense. These results also behaved very similarly to those of a study conducted by Molina et al. (2008) in which it was empirically demonstrated that $81.2 \%$ of students agreed that the main limitation identified to achieve a scientific publication is the lack of time and teaching support.

These results are similar to those obtained in a study (Yuri CR, 2018) on the limitations that students find related to scientific production and research, $61.1 \%$ consider that the main obstacle is the lack of adequate advice and 20 , $8 \%$ due to lack of time. The majority (38.2\%) consider that an appropriate strategy would be to increase the amount of time allocated to research courses to improve student scientific production. A serious problem in scientific production is that many students have never participated in scientific activities. $50 \%$ of students with no research experience reported having problems or taking a long time to research. These results could be influenced by the fact that the largest number of students surveyed were between the second and third semesters of their career. For $25.6 \%$ and $21.8 \%$ respectively. From the fourth semester onwards, $35 \%$ of the students are grouped, who are assumed to have already received the contents of Research Methodology.

In relation to the empowerment of teachers and the support in the preparation and execution of research projects, the average obtained was $3.64 \pm 1.312$ and $3.39 \pm 1.335$, an average level respectively in these indicators, the participation of teachers in scientific activity, which is similar to the data of a study carried out by Júnior Ortega $\mathrm{R}$, et al., 2018.) in which more than 55\% of the respondents indicate that their teachers express confidence in the 
abilities of the students to carry out research, as well as more than $37 \%$ of the professors, motivate and encourage them to carry out research, accompanying them from their chairs in carrying out research projects. These results are also similar to those reported by Taype-Rondán et al. (2014), who show a low participation of students in publications and projects not only in Peru but throughout Latin America.

According to Hilarraza (2012) there is a close relationship between the student's attitude and the role of the teachers responsible for teaching, since they can take advantage of their knowledge and their own research experience as a didactic resource. It is currently a challenge to, Through good articulations of this type it will be possible to generate new researchers of great potential who in the future will be able to mentor many others, building a scientific community through this virtuous circle.

Table.4: Anova of the indicators of the subdimension perception of students

\begin{tabular}{|c|c|c|c|c|c|c|}
\hline \multicolumn{7}{|c|}{ ANOVA } \\
\hline & & $\begin{array}{c}\text { Sum of } \\
\text { squares }\end{array}$ & $\mathrm{gl}$ & $\begin{array}{c}\text { Mean } \\
\text { quadratic }\end{array}$ & $\mathrm{F}$ & Sig. \\
\hline \multirow[t]{3}{*}{ Training on project development } & $\begin{array}{l}\text { Between } \\
\text { groups }\end{array}$ & 388,441 & 45 & 97,110 & \multicolumn{2}{|c|}{$164,096,000$} \\
\hline & Within groups & 216,003 & 365 & ,592 & & \\
\hline & Total & 604,443 & 370 & & & \\
\hline \multirow[t]{3}{*}{ Training on writing scientific articles } & $\begin{array}{c}\text { Between } \\
\text { groups }\end{array}$ & 405,904 & 5 & 101,476 & 176,286 & 000 \\
\hline & Within groups & 210,106 & 365 & ,576 & & \\
\hline & Total & 616,011 & 370 & & & \\
\hline \multirow[t]{3}{*}{ Laboratory operation } & $\begin{array}{l}\text { Between } \\
\text { groups }\end{array}$ & 462,703 & 5 & 115,676 & 139,059 & 000 \\
\hline & Within groups & 303,624 & 365 & ,832 & & \\
\hline & Total & 766,327 & 370 & & & \\
\hline \multirow[t]{3}{*}{ Accompaniment in research projects } & $\begin{array}{c}\text { Between } \\
\text { groups }\end{array}$ & 433,502 & 5 & 108,375 & 176,619 & 000 \\
\hline & Within groups & 223,969 & 365 & ,614 & & \\
\hline & Total & 657,470 & 370 & & & \\
\hline \multirow[t]{3}{*}{ Budget allocation to execute projects } & $\begin{array}{c}\text { Between } \\
\text { groups }\end{array}$ & 503,585 & 5 & 125,896 & \multicolumn{2}{|c|}{$239,150,000$} \\
\hline & Within groups & 192,148 & 365 & ,526 & & \\
\hline & Total & 695,732 & 370 & & & \\
\hline \multirow[t]{3}{*}{ Knowledge of the lines of research } & $\begin{array}{c}\text { Between } \\
\text { groups }\end{array}$ & 380,453 & 5 & 95,113 & 137,210 & 000 \\
\hline & Within groups & 253,017 & 365 & ,693 & & \\
\hline & Total & 633,470 & 370 & & & \\
\hline \multirow[t]{3}{*}{ Motivation towards research } & $\begin{array}{l}\text { Between } \\
\text { groups }\end{array}$ & 342,141 & 5 & 85,535 & 118,882 & 010 \\
\hline & Within groups & 262,616 & 365 & 719 & & \\
\hline & Total & 604,757 & 370 & & & \\
\hline \multirow[t]{3}{*}{ Disclosure of research activities } & $\begin{array}{l}\text { Between } \\
\text { groups }\end{array}$ & 287,567 & 5 & 71,892 & 86,730 & 050 \\
\hline & Within groups & 302,552 & 365 & 829 & & \\
\hline & Total & 590,119 & 370 & & & \\
\hline \multirow[t]{3}{*}{ Availability of time for research Between groups } & $\begin{array}{l}\text { Between } \\
\text { groups }\end{array}$ & 405,993 & 5 & 101,498 & 140,821 & 000 \\
\hline & Within groups & 263,077 & 365 & ,721 & & \\
\hline & Total & 669,070 & 370 & & & \\
\hline
\end{tabular}


Dr. Jorge Daher Nader, Dr. Amelia Patricia Panunzio, and Dr. Marlene Hernández Navarro

\begin{tabular}{|c|c|c|c|c|c|c|}
\hline \multirow{2}{*}{ Dissemination of journals to publish } & $\begin{array}{c}\text { Between } \\
\text { groups }\end{array}$ & 466,454 & 5 & 116,613 & $174,789,000$ \\
\cline { 2 - 6 } & Within groups & 243,516 & 365 &, 667 & \\
\cline { 2 - 7 } $\begin{array}{c}\text { Total } \\
\text { Empowerment of teachers of student scientific } \\
\text { activity }\end{array}$ & $\begin{array}{c}\text { Between } \\
\text { groups }\end{array}$ & 373,393 & 5 & 93,348 & $130,146,000$ \\
\cline { 2 - 7 } & Within groups & 261,799 & 365 &, 717 & & \\
\cline { 2 - 7 } & Total & 635,192 & 370 & & & \\
\hline
\end{tabular}

Own Elaboration (Daher J. 2019) $\mathrm{n}=370$ students

Next, the results obtained in the questionnaire addressed to graduates about their perception of student scientific activity at the Faculty of Medical Sciences are analyzed.

Table 5: Mean and standard deviation for the indicators of the PERCEPTION OF SCIENTIFIC ACTIVITY subdimension. Questionnaire for graduates

\begin{tabular}{|c|c|}
\hline Indicators & Mean \pm SD \\
\hline Training on writing scientific articles & $3,22 \pm 1,209$ \\
Training for project development & $3,89 \pm 1,253$ \\
Budget allocation for publishing & $1,53 \pm, 910$ \\
Laboratory operation & $1,22 \pm, 705$ \\
Accompaniment in the development of research projects & $3,61 \pm 1,546$ \\
Budget allocation to execute projects & $2,90 \pm 1,212$ \\
Disclosure of magazines to publish & $3,12 \pm 1,768$ \\
Disclosure of research activities & $3,23 \pm 1,263$ \\
Availability of time for research & $3,81 \pm 1,395$ \\
Knowledge of the research lines & $1,94 \pm 1,227$ \\
Functioning of research groups & $3,54 \pm 1,458$ \\
Existence of agreements or strategic alliances & $3,34 \pm 1,273$ \\
\hline
\end{tabular}

Own Preparation (Daher J. 2019) $n=309$ graduates

When inquiring in the graduates about training in writing scientific articles and for the preparation of projects (table 16), the data obtained were $3.22 \pm 1.209$ and $3.89 \pm 1.253$, which is at an average level, this result is similar to that obtained in the questionnaire for teachers and students in relation to these indicators. In the Faculty of Medical Sciences, training has been carried out in writing scientific articles and in the preparation of projects, but they have not been sufficient to achieve an increase in scientific production in the faculty.

Regarding the budget allocation for publishing and for the elaboration of projects, and the operation of laboratories and other physical spaces for research, the mean and SD obtained were 1.53 $\pm, 910,2.90 \pm 1.212$ and 1 , $22 \pm, 705$ in each case, these data coincide with a study carried out in Peru, (Nieto Gutiérrez, W, 2018) in which it was obtained as a result that only of the 57 institutions evaluated only six universities that have medical schools offer incentives for scientific publication, of which only two grant this bonus considering the quartile of the journal and three include students as recipients of these benefits.

Although financial resources per publication are necessary to increase the scientific production of the university, some studies have described that they can also cause a decrease in the quality of published works (Opstrup N., 2017), this could happen with higher frequency in developing countries (Aboal D, Tacsir E, 2017).

The disclosure of the journals where to publish, the disclosure of the research activities and the availability of time to publish had a mean and SD of $3.12 \pm 1.768,3.23 \pm 1.263$ and $3.81 \pm 1.395$, average level in each case. These indicators continue to be problematic today. The magazines to publish are available on the internet, and yet they are not well known. At present in the Faculty of Medical Sciences there has been a large-scale decrease in research activities, there are no longer scientific events in which teachers could disseminate the results of their research. The scarce time to do research is still a problem, more and more is the administrative load of the teachers, to which is added the large number of teaching hours that are assigned to the research professors. It is necessary to highlight 
the similarity of the results obtained when inquiring about the indicator: dissemination of the journals where in the teachers and graduates.

Knowledge of the lines of research was $1.94 \pm 1.277$, for a low level, which denotes that the graduates have no idea what the lines of research are. The lines are disseminated through different media, but it is necessary to promote their socialization, a task that corresponds to teachers or authorities. The functioning of the research groups obtained a mean and SD of $3.54 \pm 1.458$, although it is at an average level in the Faculty, there are no research groups formed. Now, recently, two research groups have been formed. For their part, the existence of strategic cooperation agreements or alliances

International obtained a mean and SD of $3.54 \pm 1.273$. These aspects result in a deficient scientific production, which coincides with the reality within a Faculty of Dentistry in Peru; in which according to the study of César Quiroz, C; 2017) of a total of 269 theses supported after 10 years, only 35 (13\%) were published in national and international scientific journals. This scarce scientific production after so long is the reflection of a poor scientific culture and encouragement towards the publication of scientific articles.

\section{SOURCES OF FUNDING}

This research received no specific grant from any funding agency in the public, commercial, or not-for-profit sectors.

\section{CONFLICT OF INTEREST}

The author have declared that no competing interests exist.

\section{ACKNOWLEDGMENT}

None.

\section{REFERENCES}

[1] Baron, Robert and Byrne and Donn. (2015). Social psychology. Mexico: Pearson. Prentice Hall. Spain. Madrid

[2] Bordons, Zulueta (1999). Evaluation of scientific activity through bibliometric indicatorsRevEspCardiol. ; 52 : 790-800 - Vol. 52 No. 10.

[3] De las Salas, (2014). Attitude of the university student towards research in the Luz nucleus - Eastern Coast of the Lake Legal Deposit: PPI200802ZU2980 / ISSN: 1856-9331. Edition No 18 - Year 9 - October 2014 - March 2015.

[4] Jiménez, Terriquez, Robles, (2011). Evaluation of the academic satisfaction of the students of the Autonomous University of Nayarit. Revista Fuente, 2 (6), 46-56 López, (2014). Quality management models. European Model of Excellence. Spain: Colegio Sagrado Corazón Jesuitas León. Available at: http://www.jesuitasleon.es/calidad/Modelos\%20de\%20gestion\% 20de\% 20calidad.pdfMantilla, (2007)

[5] Research management: differentiations and relationships. Available at: http://revistas.usta.edu.co/index.php/hallazgos/article/viewFile/1668/1817Molero, Contreras, Casanova, (2016).

[6] Knowledge management as a tool for research productivity in the university sector. Legal Deposit: PPI200802ZU2980 / ISSN: 1856-9331. Edition No 21 Muñoz, (2000). Towards an intercultural education: Approaches and Models. Complutense University of Madrid: Education meetings. 1, 81-106.D Dipsonible at: http://qspace.library.queensu.ca/bitstream/1974/628/1/sedano.pdfPezántez, (2011).

[7] Management and quality indicators of Higher Education. Master in Integrated Quality, Environment and Safety Management SystemsTeach to investigate. A new didactics in the training of researchers in social and human sciences. Mexico. Plaza and Valdés Editores Sancho, (1990).

[8] Bibliometric indicators used in the evaluation of science and technology. Bibliographic review. Rev. Esp. Doc. Cient., K3, 3-4, 19900ñate, Urdaneta, (2016). 
[9] Knowledge management for the training of researchers in university environments. Legal Deposit: PPI200802ZU2980 / ISSN: 1856-9331. Edition No 21 Ucrós, Sanchez and Cardeño, (2015). job satisfaction in teaching, research and extension, of higher education professors in Guajira Colombia. International Journal Administration \& Finance Vol. 8, No. 4, 2015, pp. 107-116. Available at: ftp://ftp.repec.org/opt/ReDIF/RePEc/ibf/riafin/riaf-v8n4-2015/RIAF-V8N4-2015-7.pdfVanderZanden, James, (1990).

[10] Manual of social psychology. Madrid: Paidos IbéricaAlonso, Tannuri, Cabrini, Pandiella, and Benavent. (2016).

[11] A bibliometric analysis in the area of Medicine: scientific collaboration between Brazil and Spain (2002-2011). Library Research: Archivonomy, Library Science and Information. Volume 30, Issue 69, May - August 2016, Pages205-230. Available at: https://www.sciencedirect.com/science/article/pii/S0187358X163002 Alvarado, Morales, Aguayo, (2016).

[12] Perception of educational quality: case applied to students of the Autonomous University of Nuevo León and the Instituto Tecnológico de Estudios Superiores de Monterrey. Revistadela educación superior printed version ISSN 0185-2760. Rev. educ. sup vol.45 no.180, Available at: http://www.scielo.org.mx/scielo.php?pid=S0185-27602016000400055\&script=sci_arttex, (2000).

[13] The Leadership of Educational Processes. In: A. Villa. (Coord). Leadership and Learning Organizations. III International Congress on Center Management. (1st ed., Chap. ISBN: 84-271-2338-00, pp. 299-330). Bilbao. Spain: Editorial Messenger Álvarez, Juncosa, (2014). 